\title{
On Some Issues of Foreign Language Course Modeling and Theory Designing
}

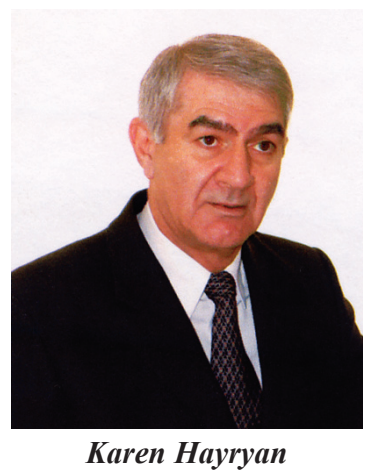
of methodologists is neither fashion nor innovation. It is conditioned by the modern problems of science development.

At present, under the conditions of the rapidly developing sciences, on the one hand, their network widens: new branches come into being on the borderline of the related sciences and, on the other hand, integration of the achievements gained in different spheres of knowledge takes place.

To find the most effective path towards a better methodological assistance the latter should involve the objects and events of both natural and social sciences meeting the current requirements of interdisciplinary scope of methodology apt to gain a deeper insight into profound and objective studies.

\section{The systemic principle of object investigation.}

In point of fact, the perspective of the utmost present-day popularity as for the methodology of scientific studies is the systemic-structural approach. This proves to be a successful outlook for object investigations revealing complete formal (morphological) paradigms and functional, in-context ranges and invariants. At the same time the pace of studies and the discoveries are concurrently observed, the facts are easily grouped and the effectiveness of the methods applied is evaluated as well.

The systemic-structural principle of object investigation acquires special importance when it is used in the methodological studies of foreign language teaching. The above stated refers both to general and special methods. It is explained by the close, sometimes complicated interconnection existing between the mentioned and related 
sciences, especially those of linguistics, pedagogy, psycholinguistics and didactics which assume a vast divergence of opinions and comments.

It goes without saying that there is a constant methodological need in their integration within the teaching process. This task is usually accomplished by proportioned separate subsystems introduced in accordance with the requirements of target levels. ${ }^{1}$

They are included into a larger system of general education as separate subsystems. The latter, respectively, is part of a larger system, that of education (professional-technical education, higher education, scientific personnel training and so on). Thus, education is a supersystem consisting of material and ideal subsystems having complicated interaction (structures of different levels) where the foreign language occupies a special place and is of special importance (Bim 1977: 16-18).

Coming to the role of foreign languages in the supersystem of education this article does not at all aim at disclosing interdependence, mutual arrangement and interaction between these various levels,, neither the importance of all the components taken separately which is of certain priority for solving the problems of foreign language teaching. In the present article our focus is on the components which, to our minds, can serve a theoretical basis in clarifying several essential problems connected with the improvement of current courses. From the theoretical point of view the issues under discussion concern all the foreign language courses taught at various educational institutions.

\section{The general outline of the object.}

The level of the progress of the society has always depended on man's knowledge of the surrounding world and his ability to influence things and phenomena through it. In this respect, since ancient times there has always been a need for recording the knowledge of natural and social phenomena acquired by mankind.

A vast number of things and phenomena surrounding us have been described in detail at different times. But at a certain period it became clear that the descriptions were too large in volume and it was impossible to process and perceive the whole informational flow.

The continual growth of the volume and value of information sets forward every time newer problems of social concern come into view. Even the simplest calculations definitely show that it is beyond the power of an individual to skillfully process and apply that huge informational heritage (Andrianova 1980: 44-59).

To overcome this, modern science suggests a selected choice of a limited amount from the vast amount of information. Yet, the selected information should not be accidental, It should be of utmost significance and importance from the perspectives of mere description, social interaction and informative interchange.

In other words, giving the general outline of the reality becomes a priority for science.

And how does the generalization of the reality take place?

The reality, i.e. the surrounding world, seems infinite at first sight; however science has worked out generalized concepts to describe it. For example, being a product of the 
results and observations of separate branches of science, dialectical categories gradually turned into philosophical ones describing the world in a more generalized way. The generalized description of the world obtained in this way can be used for the scientific study of separate objects (Jahukyan 1978: 10).

Thus, it is the demand of the times to be guided by the above mentioned principle when describing an object.

\section{The structural model of the system.}

The success of a scientific research largely depends on the ability to survey into a complicated problem analysing it into simple parts for comparing them, maintaining the essential peculiarities of the object at the same time.

In other words, to know a subject means to know the regularities of its structure. The object chosen for research purposes does not always have a structure that can easily be observes and perceived and the aim of the researcher first of all should be to expose the linguistic system unveiling all the components in correlation involved in the given language structure. If we assume that the object of the study is the process of teaching a language, the aim of the researcher should be to reveal its structure with all its correlated components. Consequently, the necessity for revealing its hidden structure should be considered as one of the objectives of the science of language teaching.

The target object under investigation together with its constituent parts and functions makes a three-fold union which actually assumes the concept of system (Bim 1977: 6).

If the elements of a certain system are not obvious, and the system exists and is in action, this means that its components undoubtedly exist. Investigating the elements of a system, it's possible to apply a method by which the elements can be predetermined. If we manage to build an imaginary system, which would correspond to the researcher's notion of a system to a considerable extent, the supposed system can be considered the model of the object under investigation. ${ }^{2}$

Having abstraction as its basis, modeling is imagining the object under research in its structure, when the image of the object is restored on the basis of outward appearance and generality of structure and functions. The simplification of the given set of structural components takes on the systemic-structural principle and is aimed at the internalization of the object under study with all the relevant concepts to be created in thought (Novik 1965: 3).

Thus, the model is the structural version of the decreased scale of an object or phenomenon which is built up based on the facts and hypotheses.

\section{The model version of the system of foreign language teaching.}

Foreign language teaching is a double-sided process of conveying and acquiring knowledge and skills. It is accompanied by a great number of ideal and material components, each of which has its role and significance. Thus, the process of foreign language teaching can become a subject of investigation from various points of view, e.g. educational (pedagogic), content of teaching (didactics), practical aims (pragmalinguistics), general and special methods (methodology) and so on. 
Consequently, before passing on to the structuring of course modeling, the researcher must have a definite orientation.

One of the possible versions of building up a foreign language teaching model is the linguistic one, when the object of investigation is the system of the language being taught. From this point of view the structural model of the language system being taught can be considered a hypothetical system in the way adopted in accordance with the modern data on the science of the given language. It is quite possible that this model is not unique; it is one of the possible divergent models. It is supported by the presence of different grammatical descriptions of the same language, written at different times and from different scientific viewpoints.

Assuming the system of a given language as a basis, the author of the supposed model, in this case too, must have a definite orientation, i.e. approach its structuring from the perspective of the predetermined branch of linguistics.

"Language is not just separate words or sentences, but a coherent text..." Besides, we must differentiate between the text of the whole work or the so-called macrotext and from the overphrasal unity /complex syntactic entity/, the microtext (Moskalskaya 1981: 12-13).

Work on written and oral texts constitutes a basis for a foreign language course, being structured by the principle of communicative trend. From this point of view the efficient realization of a foreign language course is mainly conditioned by the usage of texts providing a high productivity of teaching. As to the efficiency of instructive texts, there is a criterion of formal character which is conditioned by a number of factors: to what extent the given text favors the development of the ability to communicate in the target language within the limits of the syllabus. Thus, the realization of the practical and educational aims set before a foreign language course depends both on the texts used in textbooks and on the oral and written modeled ones being presented to learners during the course.

It is known that the problems connected with the formation, analysis, evaluation, as well as disclosing the hidden educational potential of the text and those connected with raising their efficiency are mainly discussed within the framework of text linguistics (grammar) and text theory.

Some problems connected with the modeling of educational texts, i.e. compiling and elaborating efficient versions, are discussed below in the light of text theory.

\section{The key problems of building up a text model.}

In an attempt to study an instructive text and to build up its model, the textual unit should be observed as a compound totality of constituents. For example, when modelling a text one of the approaches applied is to take a text model as a combination or succession of structural units (sentences) underlining their function in the given textual unit. Thus, the whole task is subtracted into a list of structural variants of sentences involved (Bertalanffy 1976: 36-37).

A good index for the conformity of the model can be considered the absence of contradictions in the interaction of functional elements of the system. Providing the 
efficient work of the constituents of the text system is conditioned by the concept of the relationship existing between a part and a whole. Any element of the structural variant of a sentence, included into the text model, occupies a lower position as compared with a sentence. Anyhow, all the elements constituting a system are interconnected.

It is also important to understand the qualitative and quantitative differences between those elements having in mind that quality is the invariable feature of an object, while quantity is its changeable feature. In the light of this theory the classification of sentences could be a precise instrument to single out the relatively persistent textual constituents, i.e. the syntagmatic lines of paradigmatic elements, while elements forming paradigms in syntagmatic lines must be considered less stable, consequently relatively not so important aspect of the language. Anyhow, this does not mean that the latter are not essential, vice-versa, the functioning of the whole system is impossible.

The elements forming paradigms in the system of the text, i.e. separate parts of speech entering the sentence structure, are not important from the point of view of effective foreign language teaching, since, as compared with syntagmatic structures they do not develop the researcher's creativity.

Assuming that the time scheduled to foreign language teaching must be economized, the above mentioned approach can be useful in terms of limiting the volume of teaching materials if preference is given to the qualitative and not to the quantitative aspect of the text. It follows from the above stated that when structuring an instructive text model, a so-called rough model can be supposed beforehand based on the enumeration of syntagmatic structures set up by the given syllabus, and the textual components within these structures (according to different textual patterns) can be observed from the viewpoint of the course designed.

The elements involved in the given text according to the patterns and structural peculiarities of lexical and/or phraseological character are occasional and constitute the quantitative aspect of the language, while the qualitative differences are typical of the constructive elements of the text model.

There aren't any primary and secondary categories in the model designed for research purposes, i.e. the model either functions entirely or doesn't function at all. By referring to the text system model from this perspective we assume that the constructive constituents it must be understood in the following was: constructive constituents can include elements of different number, one or more. Hence, these constituents constituent structures, irrespective of the number of the elements included in it. It mustn't be forgotten that all the constructive elements are full and equal members of the model, and the absence of any of them can be the reason for the failure of the model (Moskalskaya 1971: 5-15). Thus, we may conclude that the constructive elements, which differ as for the degree of definiteness and are distributed according to the textual patterns, may serve as guidelines for outlining the model needed.

Structuring the model of an instructive foreign language text corresponds (according to some qualitative constituents) to the problem of singling out the invariables from the context, which is recognized as an information theory problem, as 
this theory tends to discover the language of communication (Chomsky 1965: 3-9). Speaking about the quantitative orientation of structuring a text model, it must be mentioned that as a matter of fact such structures are formal as they predetermine the form of the text only.

In general, the formal aspect of knowledge differs from its main content so far as formal and material rules differ from each other. Whatever is connected with the material content of knowledge is to do with its quantitative characteristics. As to the qualitative characteristics of knowledge, it assumes formal methods of knowledge and reflects the essence of relationships existing between systems and the reality (Gousserl 1909: V-VI).

\section{The theoretical grounds of designing a text model.}

As a matter of fact, the aim of the theory is to study and to describe phenomena and a great number of facts of the reality in a generalized way. For that matter the theory should be designed in such a way that each element should correspond to the great number of phenomena and facts of the reality reproduced in the theory.

Any scientific theory is a strictly regulated conceptual system, which has a rather complicated structure and is a perfect means of reflecting the objective reality. A theory is considered to be formulated if its other characteristics are determined, i.e. structure categories and the correlation of their elements (Kuznetsov 1968: 72, 83).

The theory keeps all the aspects integrated due to its cornerstone, namely, the sign which marks all the separate concepts and segments of information referring to the reality expressed and/or addresses to.

The sign is unaltered both towards the reality (the object to be expressed) and the perspective of internalization of the reality (the methodology of expression). Besides, every sign is invariable not only towards the variants expressed by it but also towards all the other signs of the structure of the theory. The signs are not alike, because there are qualitative differences between the facts correlating to each sign. The signs differ from each other by qualitative characteristics.

If we study a text describing the reality, we won't fail to notice that it consists of successively arranged signs. Each recognizable sign in the text describes some event or situation. As their number in the sign system is limited and the events and situations are innumerable, it is clear that each sign corresponds to a number of events and situations, which are characterized not only by multiplicity but also by diversity. Whereas the signs are characterized not only by the limitations in the quantity, but also by certain stable quality, which is invariable for all the cases of events and situations described by the same sign.

As is seen, the main characteristics of the text is its quality or its qualitative difference from other signs in the system, and the main characteristics of the phenomena and facts of the reality is the quantity, the number of events included in the same paradigm.

The events referred to are singled out with all the distinguishing features only due to the contextual frames. Correspondingly, all the qualitative differences are observed and expressed through the relations between different signs, which are not events but 
classes of events and the characteristics of classes of events, i.e. the number of events forming a separate class, is the essential feature of the given class, as even the approximately outlined limits single out that class, i.e. determine the qualitative differences existing between different classes and serve a basis for formulating those signs with an aim to design a theory.

Thus, setting up a quantitative description of the phenomena and facts of the reality reflected through the sign, we obtain the qualitative characteristics of the separate constituents formulated by the sign, with the help of which philosophical relation between quantity and quality is revealed.

Proceeding from the general approach to the sign system, not only words of the text, numbers and punctuation marks, but also sentences are considered to be signs. However, the signs include not only separate sentences of the text but also types of sentences (Wittgenstein 1961: 44-46).

One of the characteristic peculiarities is that being invariable they maintain the relative importance towards each other, i.e. they appear to be abstract criteria of different possibilities reflecting the reality.

The place they occupied in the hierarchy of signs is conditioned by their ability to express phenomena and facts of the reality. The more facts the given sign includes, the higher is its variability and consequently the role it occupies in the hierarchy.

Thus, a mere informative text delimits the possibilities of using figures of speech. The priority of informative function lays a special stress on quantitative, qualitative and functional peculiarities of an object or phenomenon. So, the discourse involves concepts referring to them within the paradigms. From this point of view the set expressions and types of sentences representing structures are invariable not only towards the signs included in them, but also towards all the signs which can occupy a place in the above mentioned syntagmatic lines without breaking those structures.

Thus, the higher the abstraction of the sign, the more concrete it represents the theory, i. e. it is invariable towards a great number of phenomena and facts of the reality, reflecting them in a brief and generalized way.

In general, any correlation between the sign and the reality expressed by it can be understood as a usage of a linguistic unit towards the fact or concept. If in that respect we study the language as a whole, it can be characterized as a means of perceiving and expressing the reality. In the same sense an instructive text in a foreign language is the basis for building up and developing skills for promoting communication in some aspect of reality.

Work on developing many-sided communicating skills through oral and written texts lies in the basis of foreign language course modeling by the communicative-verbal principle.

Teaching based on monologues and dialogues is an effective means of building up and developing not only oral communication skills, but also other harmonious skills, mainly, hearing, reading and writing.

Thus, any instructive text in a foreign language, both written and oral, has a more important primary aim, that is teaching types of communication parallel to conveying 
information to learners. In order to properly organize foreign language courses in various educational institutions ans sections it is necessary to be guided by a theory which is based on teaching more invariable units of the text, i.e. syntagmatic structures meeting the syllabus requirements.

It can be concluded from the above stated that theory in question can serve as a stable basis for promoting skills in communicating in a foreign language.

Such a theory is complete in nature and what is more important, in a short period of time it gives much with little means and has great potential.

\section{Notes:}

1. The definite aims set before the general teaching course and the given foreign language course, the same foreign languages taught and the methods and ways of teaching those languages, related sciences and so on constitute as ideal components. Teaching plans and syllabi, textbooks and subsidiary materials, as well as any other teaching means involved in the teaching and learning process constitute as material components.

2. The object of astronomy can serve as an example of this. It is common knowledge that many stars have planetary systems. But it is impossible to get any information on them by direct observation due to the long distance. However, deflections taking place in the movement of those stars testify to the existence of planetary systems which is also supported by mathematical calculations.

\section{References:}

1. Bim, I.L. (1977) Metodika obucheniya inostrannim yazikam kak nauka i problemi shkolnogo uchebnika. Moskva: Izd. Russki Yazik.

2. Andrianova, T.V. (1980) Metodicheskiye problemi organizatsii informatsii $v$ obshchestvennikh naukakh. Moskva: Izd. Nauka.

3. Jahukyan, G.B. (1978) Obshcheye i armyanskoe yazikoznaniye. Yerevan: Izd. AN Arm. SSR.

4. Novik, I.B. (1965) O Modelirovaniye slozhnikh system. Moskva: Izd. Misl.

5. Moskalskaya, O.I. (1981) Grammatika Texta. Moskva: Izd. Vishaya Shkola.

6. Bertalanffy, L. (1976) General System Theory. New York: George Braziller.

7. Chomsky, N. (1965) Aspects of the Theory of Syntax. M.I.T. Press.

8. Gusserl, E. (1909) Logicheskiye issledovaniya // Noviye ideyi v filosofii. Sankt Peterburg: Obrazovaniye. Vol. 1.

9. Kuznetsov, I.B. (1968) Struktura nauchnoy teorii i struktura ob'ekta // Voprosi filosofii. N5.

10. Wittgenstein, L. (1961) Tractatus Logico-Philosophicus. (Tr. by Pears O.F.; McGuinness, B.F.) London: Routledge and Kegan Paul. 


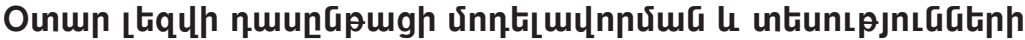 qunnıgưua up puap hungtip}

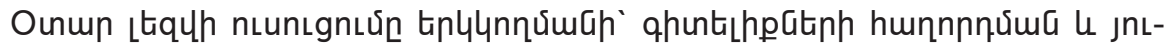

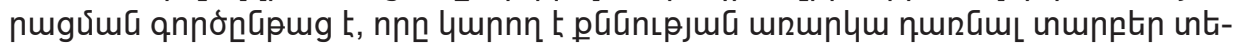

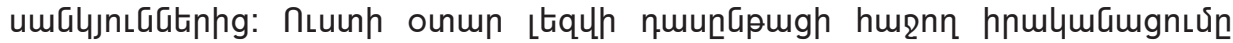

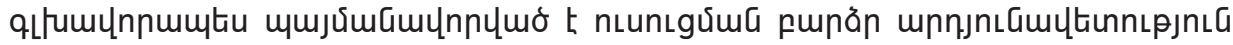

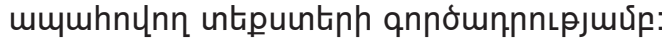

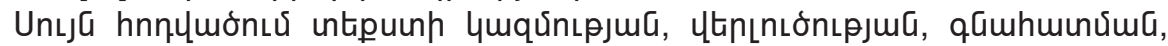

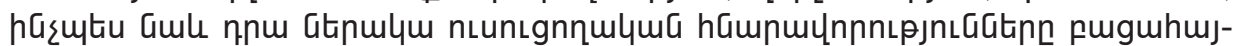

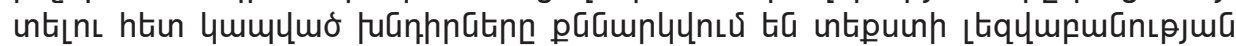

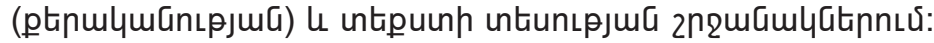

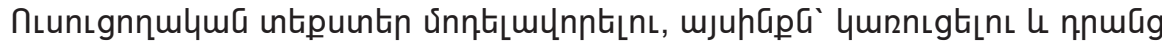

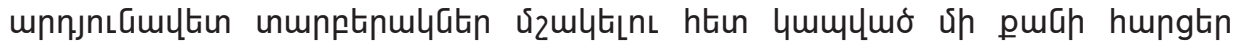

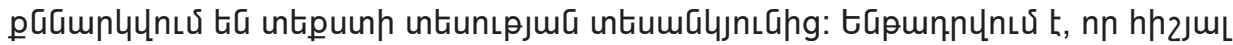

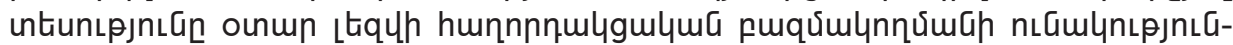

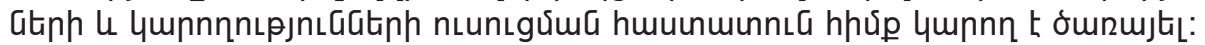

